\title{
New Moon’s Visibility Criterion Based on Photometric Data
}

\author{
Ahmed Kamil Ahmed \\ Department of Astronomy and Space, College of Science, University of Baghdad, Baghdad, Iraq
}

\begin{abstract}
The elongation (or arc of light) is the angular separation between the sun and the moon. It has taken as key factor that contributed to lunar crescent visibility criterion. Moreover, the time of crescent sighting, in case of topocentric calculations, was chosen as reference frame to assess the new moon visibility by taking its brightness contrast. The sky brightness conditions are measured during the clear nights of the lunar crescent that expected to be visible (i.e. clouds not present and a low aerosol loading). In addition, 43 of positive observations (successful) for lunar crescent from Malaysia, Teluk Kemang location, have been studied and analysed. The data employed to obtain the estimate values of sky brightness and have been correlated between moon elongation and solar altitude as well. The findings showed that the range of sky brightness for lunar crescent visibility is 0.05-167.802 lux. The moon elongation should be 11.331 and the solar depression angle should be 0.5 for the highest sky brightness value of 167.802 lux. Finally, the new moon visibility threshold, the moon elongation must be $\geq 8.5^{\circ} \pm 0.1^{\circ}$.
\end{abstract}

Keywords: Moon's Visibility, Sky Brightness, Moon's Elongation, and Brightness Contrast

\section{Introduction}

Most often in astronomy the instance of lunar conjunction is referred to as the new moon [1]. The moon is always invisible from the earth at the time of conjunction. When the moon first becomes visible again (usually more than half a day after the astronomical new moon), observers see a young crescent moon. Much effort has been put by the astronomers to match predictions with observations. Contrary to common belief, young crescent visibility has been difficult to predict accurately despite great strides being made in positional astronomy and related sciences [2]. The difficulty of observed the young crescents due to the poor air transparency, haze, humidity, pollution, chronic cloudiness, and other hindrances to observing the celestial sky [3].

The search for simple and precise criteria with different approach is still useful in the process of unification of the Islamic calendar [4]. There are two approaches to determine the first visibility of lunar crescent either of empirical or theoretical methods. The empirical method is based on analyzing the collection of observational data. The criterion formulation is depending on the analysis of results according to best parameter used of observation. On the other side, the theoretical method depends on the various factors affecting crescent visibility that can be used to design descriptive mathematical model [5].

Methods for predicting first (or last) sighting of the new (or old) lunar crescent have been required and researched since the time of the Babylonians [6]. The Babylonian criterion stated that the young crescent is visible to the naked eye if at the moment of observation, the arc of vision (angle between the moon and the sun) exceeds $12^{\circ}$ [7]. The angles are defined for the relative locations of the crescent, the sun, and the horizon relative to the observer as shown in Figure (1). This method, a rule for whether the crescent will be visible or not at that specific time and place can be computed with these angles. After that, Muslim astronomers, like the AlBattani, Al-Farghani, Al-Biruni, and Al-Tusi, approached the problem in a similar way. They obtained limiting values between $\left(9.5^{\circ}-12^{\circ}\right)$.

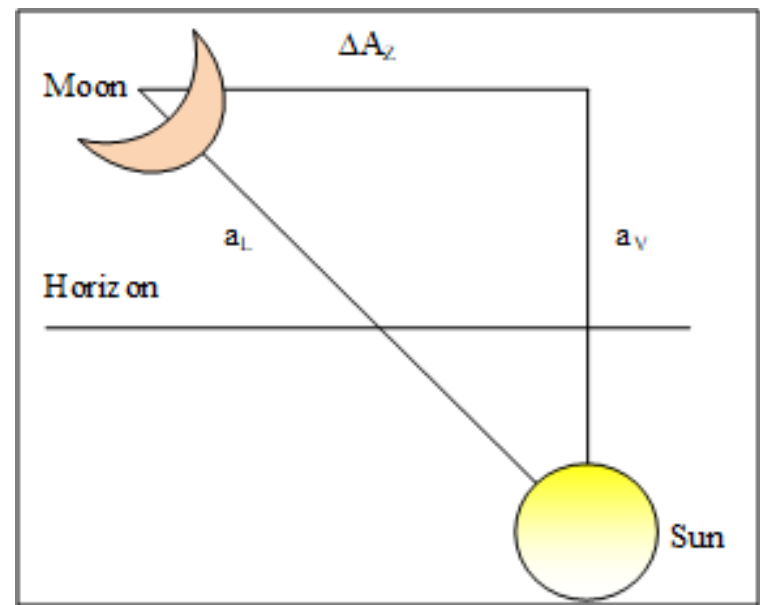

Figure 1: Basic geometric variables for crescent visibility prediction, where $\left(\mathrm{a}_{\mathrm{L}}\right)$ arc of light, $\left(\mathrm{a}_{\mathrm{V}}\right)$ arc of vision, and

$\left(\mathrm{A}_{\mathrm{Z}}\right)$ difference in azimuth [7]

However, over the years, a lot of models for lunar crescent visibility adopted each of the physical and geometric type. In brief, Fotheringham [8], Maunder [9], Danjon [10], Bruin [11], McNally [12], Schaefer [7], Ilyas [13], Yallop [14], Fatoohi [15], and Caldwell and Laney [3], as well as Odeh [16], and recently Hasanzadeh [17] have developed empirical methods for predicting first visibility of the new moon. Each of them made an observations collection of the first sighting of the young crescent and used statistical analysis to find a minimum elongation for the moon to be first seen: $12^{\circ}$ for Fotheringham, $11^{\circ}$ for Maunder, $10^{\circ}-10.5^{\circ}$ for Yallop and Ilyas [15], 7.5 for Fatoohi, $7^{\circ}$ for Danjon and Schaefer, $6.4^{\circ}$ for Odeh, and $5^{\circ}$ for McNally and Hasanzadeh.

Finally, today there are accurate criteria for knowing where and when the young crescent can or cannot be seen. Atmospheric conditions are difficult to predict locally, and so the accuracy of crescent visibility predictions is specific to that region. Hence, the objective of this research is to find

\section{Volume 6 Issue 12, December 2017}




\section{International Journal of Science and Research (IJSR) \\ ISSN (Online): 2319-7064}

Index Copernicus Value (2016): 79.57 | Impact Factor (2015): 6.391

a new criterion based on contrast between the crescent elongations correlated with sky background during the time of sunset (i.e. this work trying to propose the range of sky brightness to observe the lunar crescent).

\section{Night Sky Brightness}

The contrast in the context of first lunar crescent visibility is defined as ratio of the two components, the illumination of the lunar crescent and sky brightness [18]. There are effects of meteorological and atmospheric conditions on night sky brightness. The sky brightness depends on the geometry of the sun, the earth and the moon, the distance between the moon and the sun as well as the distance between the moon and the earth [4], additionally the geographical latitude of the site, the elevation of the site above sea level, the season of measurements, and aerosol pollution at the site as well [19]. Therefore, along of the year the appearance of crescent in one place will vary in contrast [4].

\section{Moon's Elongation Calculation}

The separation between the sun and the moon is known as elongation or the arc of light $\left(a_{L}\right)$. The elongation of the crescent at the time of observation that constitutes an important factor as it is directly related to the moon's brightness. In terms of $\left(\mathrm{a}_{\mathrm{L}}\right)$ the phase of the moon is given by Qureshi [20]

$$
\text { Moon's Phase }=\left(1-\operatorname{Cos}\left(a_{L}\right)\right) / 2
$$

The angle between the sun-moon and earth-moon angle and the elongation has the relation with illumination (or phase) [21]:

$$
\text { Illumination }=1 / 2 \times(1-\cos (\text { Elongation }))
$$

For small angles, the illumination is proportional the square of the elongation. As can be seen from the following equation [14], the elongation takes the declination angle into consideration:

$\cos ($ Elongation $)=\cos ($ Phase $) \times \cos ($ Declination $)$

\section{Methodology}

In this study, two equipments have used namely the human eye and the light meter. A light meter is a device used to measure the amount of light. The observation of western sky brightness using a light meter was performed between 2007 until 2009 [22]. The Teluk Kemang Negeri Sembilan at Malaysia has been chosen for data collecting in accordance of photometric moonless nights. The geographical coordinates of latitude is $2^{\circ} 27^{\prime}$ north and longitude is $101^{\circ}$ $51^{\prime}$ east. The light meter was fixed at altitude about $5^{\circ}$ above the horizon facing an obstruction free open sea in the western sky as well as the data has been collected every two minutes. The observations were carried out before and after sunset depending on moon and sun positions. Additionally an analytical software based on the Python's PyEphem astrometry library and FORTRAN-90 were developed to calculate the physical geometry of the sun and moon as well as to determine the moon elongation and a correlation with simulated sky brightness.

\section{Results and Analysis}

Sky Brightness Measurements: The data collected on 7 April 2008 have chosen as the reference (Table 1) to determine the sky brightness value with moon elongation for reported data from 2000 to 2010 [23]. The data collected was recorded before and after sunset. Besides that, Figure (2) shows the relationship between averaged sky brightness versus solar altitude on 7 April 2008 in Teluk Kemang, Malaysia.

Table 1: Sky brightness measurements recorded on 7 April 2008 with the solar altitude calculation as well

\begin{tabular}{|c|c|c|}
\hline Time of Reading & Sky Brightness (lux) & $\begin{array}{c}\text { Solar Altitude } \\
\text { (degree) }\end{array}$ \\
\hline $19: 10$ & 700 & 1.450 \\
\hline $19: 12$ & 570 & 0.954 \\
\hline $19: 14$ & 400 & 0.458 \\
\hline $19: 16$ & 270 & -0.036 \\
\hline $19: 18$ & 140 & -0.532 \\
\hline $19: 20$ & 110 & -1.028 \\
\hline $19: 22$ & 80 & -1.524 \\
\hline $19: 24$ & 54.1 & -2.020 \\
\hline $19: 26$ & 34.6 & -2.515 \\
\hline $19: 28$ & 22.6 & -3.011 \\
\hline $19: 30$ & 18.6 & -3.507 \\
\hline $19: 32$ & 10.4 & -4.002 \\
\hline $19: 34$ & 5.8 & -4.498 \\
\hline $19: 36$ & 3.6 & -4.993 \\
\hline $19: 38$ & 2.3 & -5.489 \\
\hline $19: 40$ & 0.9 & -5.984 \\
\hline $19: 42$ & 0.6 & -6.480 \\
\hline $19: 44$ & 0.3 & -6.975 \\
\hline
\end{tabular}

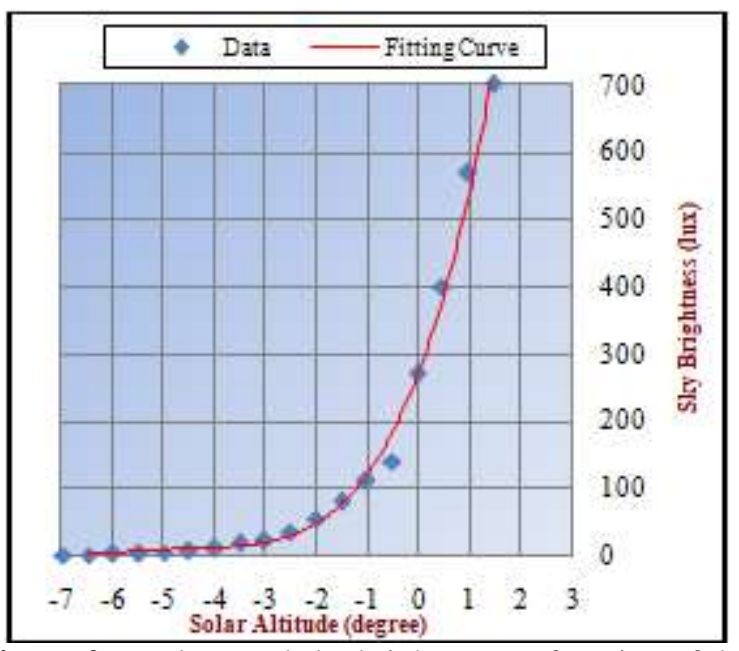

Figure 2: Background sky brightness as function of the solar elevation angle on 7 April 2008 in Teluk Kemang, Malaysia

From Figure (1), the polynomial function of $4^{\text {th }}$ order fitted to the data has been deduced for lest square-approximation. It has been to calculate the simulated sky brightness (lux). The polynomial function is obtains from least-squares fit as follows:

$$
Y=0.3681 X^{4}+7.7766 X^{3}+60.189 X^{2}+206.14 X+275.2
$$




\section{International Journal of Science and Research (IJSR) \\ ISSN (Online): 2319-7064}

Index Copernicus Value (2016): 79.57 | Impact Factor (2015): 6.391

Where $\mathrm{X}$ is the sun altitude in degree, and $\mathrm{Y}$ is the simulated sky brightness in lux. The coefficient of determination, $\mathrm{R}^{2}$, obtained is 0.9944 .

Lunar Crescent Visibility: In this work, 43 of lunar crescent observations from Malaysia (Teluk Kemang location) have been studied and analysed. The data consisted visible observations successful by optically aided and naked eye. The results have been presented in Figure (3), in case of topocentric calculations, at the time of crescent sighting. It depicts the relationship between the moon elongation and solar altitude in degrees against the simulated sky brightness in lux.

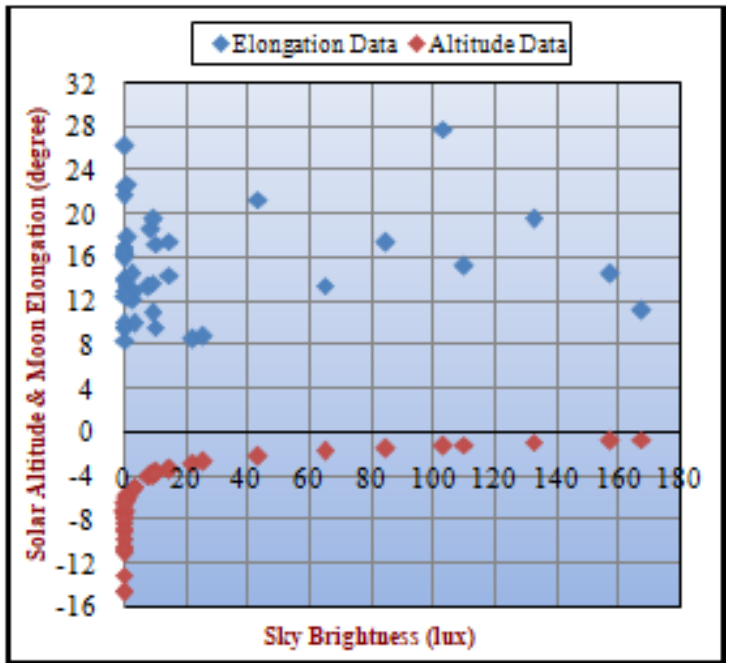

Figure 3: Relationship between moon elongation and solar altitude versus simulated sky brightness

\section{Discussion}

The observations of sky brightness were made to soon before and after sunset then the sky is too bright to pick out the faint young crescent. The sky brightness reading, just after the time of sunset, by light meter was high due to the sky still bright. The sun has dropped below horizon, after that, and making the solar depression angle. The higher probability to see the moon crescent, the solar depression angle is being larger due to the sky becomes darker. Figure (3) represented the moon elongation and solar altitude versus simulated sky brightness for lunar crescent was seen from 2000 to 2010 in Teluk Kemang, Malaysia.

The higher moon elongation gives the larger probability of crescent sighting. This is due to, at time of sunset, the moon position is high above the horizon. The data of moon elongation, in Figure (3), could noted of 33 out of 43 visible observations, showed as high as $8.523^{\circ}$ up to $26.388^{\circ}$ with sky brightness 0.05 to 14.916 lux. This condition needs the sky to be appropriately dark. Also, there are data of young crescent was seen at higher sky brightness. Two data was recorded with maximum sky brightness of 157.665 and 167.802 lux fitted for moon elongation in the range $11.331^{\circ}$ and $14.536^{\circ}$. The crescent visibility occurred with sky brightness at 22.375 lux and 132.565 lux with moon elongation $8.632^{\circ}$ and $19.700^{\circ}$ respectively. The maximum value of sky brightness recorded when a crescent was seen at 167.802 lux. For solar altitude higher than $-0.565^{\circ}$, there is still no crescent observed in the recorded data. This presents clearly that the lunar crescent should be observed after the time of sunset. A sky brightness maximum for crescent visibility is considered to be 167.802 lux, a minute of elapsed time after sunset with $0.5^{\circ}$ of sun depression angle and $11.331^{\circ}$ of moon elongation. Finally, the potential range value of sky brightness for crescent sighting is between 0.05 to 167.802 lux

\section{Conclusion}

The scientific considerations are best way to predict the lunar crescent visibility that combines the methods of calculation and the successful crescent observations. The findings showed that the range of sky brightness for lunar crescent visibility is $0.05-167.802$ lux which corresponds to $22.435^{\circ}-11.331^{\circ}$ moon elongations respectively. The highest sky brightness value (167.802 lux) corresponds to moon elongation between the moon and the sun should be 11.331 and the solar depression angle should be 0.5 . On top of that, the current study has been deduced that the threshold of lunar crescent visibility, the moon elongation must be $\geq 8.5^{\circ}$ $\pm 0.1^{\circ}$.

\section{Acknowledgments}

I would like to deeply thank Universiti Sains Malaysia (USM) of providing support for this project titled "Photometric Data of Young Moon and Visibility Criterion for the Islamic Calendar", through the research grant number (1001/PFIZIK/846078) and the Ministry of Higher Education and Scientific Research, Iraq, as well.

\section{References}

[1] Abdul Aziz, A.H. and Ahmed, A.K. (2014) A Unified Islamic Calendar Proposal for the World. Middle-East Journal of Scientific Research, Vol. 22, No. 1, pp. 115120.

[2] Ahmed, A.K. and Abdul Aziz, A.H. (2014) Young Moon Visibility Criterion Based on Crescent Illumination and Sky Brightness Contrast Model. Middle-East Journal of Scientific Research, Vol. 21, No. 9, pp. 1641-1644.

[3] Caldwell, J.A.R. and Laney, C.D. (2001) First Visibility of the Lunar Crescent. SAAO, African Skies, No. 5, pp. 15-23.

[4] Raharto, M., Arumaningtyas, E.P. and Sopwan, N. (2010) Theoretical Contrast for Hilal Visibility Prediction at Pelabuhan Ratu. AIP Conf. Proc. Vol. 1325, pp. 105-108.

[5] Fatoohi, L.J., Stephenson, F.R. and Al-Dargazelli, S.S (1999) The Babylonian First Visibility of the Lunar Crescent: Data and Criterion. JHA, xxx, pp. 51-72.

[6] Fouka, M. (2010) Visibility of the Thin Lunar Crescent [Online]. Available from World Wide Web: https://www.researchgate.net/publication/252220350_ Visibility_of_the_Thin_Lunar_Crescent.

[7] Schaefer, B.E. (1988) Visibility of the Lunar Crescent. Quarterly Journal of the Royal Astronomical Society, Vol. 29, pp. 511-523.

\section{Volume 6 Issue 12, December 2017}




\section{International Journal of Science and Research (IJSR) \\ ISSN (Online): 2319-7064 \\ Index Copernicus Value (2016): 79.57 | Impact Factor (2015): 6.391}

[8] Fotheringham, J.K. (1910) On the Smallest Visible Phase of the Moon. Monthly Notices Roy. Ast. Soc., Vol. 70, pp. 527-531.

[9] Maunder, E.W. (1911) On the Smallest Visible Phase of the Moon. Journal of British Astronomical Association, Vol. 21, pp. 355-362.

[10] Danjon, A. (1932) Jeunes et Vieilles Lunes. L'Astronomie, (Societe Astronomique de France), Vol. 46, pp. 57-66.

[11] Bruin, F. (1977) The First Visibility of the Lunar Crescent. Vistas in Astronomy, Vol. 21, pp. 331-358.

[12] McNally, D. (1983) The Length of the Lunar Crescent. Quarterly Journal of the Royal Astronomical Society, Vol. 24, pp. 417-429.

[13] Ilyas, M. (1994) Lunar Crescent Visibility and Islamic Calendar. Quarterly Journal of the Royal Astronomical Society, Vol. 35, pp. 425-461.

[14] Yallop, B.D. (1998) A Method for Predicting the First Sighting of New Moon. Technical Note No. 69, HM Nautical Almanac Office, Royal Greenwich Observatory, Cambridge, UK. NAO.

[15] Fatoohi, L.J., Stephenson, F.R. and Al-Dargazelli, S.S. (1998) The Danjon Limit of First Visibility of the Lunar Crescent. The Observatory, Vol. 118, pp. 65-72.

[16] Odeh, M.S. (2004) New Criterion for Lunar Crescent Visibility. Experimental Astronomy, No. 18, pp. 3964.

[17] Hasanzadeh, A. (2012) Study of Danjon Limit in Moon Crescent Sighting. Astrophys Space Sci., Vol. 339, pp. 211-221.

[18] Hoffman, R.E. (2003) Observing the New Moon. Mon. Not. R. Astron. Sco., Vol. 340, pp. 1039-1051.

[19] Mikhail, J.S., Asaad, A.S., Nawar, S. and Hassanin N.Y. (1995) Improving the Crescent Visibility Limits Due to Factors Causing Decrease in the Sky Twilight Brightness. Earth, Moon and Planets, Vol. 70, pp. 109121.

[20] Qureshi, M.S. (2005) Computational Astronomy and the Earliest Visibility of Lunar Crescent. University of Karachi, Pakistan, pp. 1-20.

[21] ÖZLEM, A. (2014) A Simplified Crescent Visibility Criterion [Online]. Available from World Wide Web: http://www.icoproject.org/pdf/ozlem_2014.pdf.

[22] Mohd Nawawi, M.S. A., Zainuddin, M.Z., Ahmad, N., Abdul Niri, M., Man, S., Abdul Wahab, R., Ismail K. and Zaki, N.H.A. (2012) Application of Scientific Approach to Determine Lunar Crescent's Visibility. Middle-East Journal of Scientific Research Vol. 12, No. 1, pp. 96-100.

[23] Ahmed, A.K. (2014) New Criteria for Crescent Visibility Based on Sky Brightness Leading to Global Lunar Calendar Development. PhD thesis, Universiti Sains Malaysia (USM). 